Int. J. Electrochem. Sci., 15 (2020) $394-411$

International Journal of

ELECTROCHEMICAL

SCIENCE

$\underline{\text { WwW.electrochemsci.org }}$

\title{
Galvanic Corrosion of Ti6Al4V Coupled With NiCr as a Dental Implant Alloy in Fluoride Solutions
}

\author{
Camila Dias dos Reis Barros ${ }^{1}$, Janaina Cardozo Rocha², Bernardo Ferreira Braz ${ }^{3}$, \\ Ricardo Erthal Santelli ${ }^{4}$ and José Antônio da Cunha Ponciano Gomes ${ }^{5}$
}

${ }^{1}$ Dentistry, D Sc. Student, LabCorr (Corrosion Laboratory), Department of Materials and Metallurgical Engineering (COPPE/UFRJ). Federal University of Rio de Janeiro, Department of Materials and Metallurgical Engineering (COPPE/UFRJ), Av. Horácio de Macedo 2030 Bloco I Cidade Universitária, Rio de Janeiro, Brazil.

${ }^{2}$ Chemical, Research Staff, LabCorr (Corrosion Laboratory), Department of Materials and Metallurgical Engineering (COPPE/UFRJ). Federal University of Rio de Janeiro, Department of Materials and Metallurgical Engineering (COPPE/UFRJ), Av. Horácio de Macedo 2030 Bloco I Cidade Universitária, Rio de Janeiro, Brazil.

${ }^{3}$ Chemistry, DSc. Student, LaDA (Analytical Development Laboratory), Department of Analytical Chemistry (PGQu/UFRJ). Federal University of Rio de Janeiro, Av. Athos da Silveira Ramos, 149 Centro de Tecnologia, Bloco A, Sala 517 Cidade Universitária, Rio de Janeiro, Brazil.

${ }^{4}$ Chemistry, Coordinator, LaDA (Analytical Development Laboratory), Professor, Department of Analytical Chemistry (UFRJ). Federal University of Rio de Janeiro, Av. Athos da Silveira Ramos, 149 - Centro de Tecnologia, Bloco A Sala 517 Cidade Universitária, Rio de Janeiro, Brazil.

${ }^{5}$ Metallurgical Engineering, Coordinator, LabCorr (Corrosion Laboratory), Professor, Department of Materials and Metallurgical Engineering (COPPE/UFRJ). Federal University of Rio de Janeiro, Department of Materials and Metallurgical Engineering (COPPE/UFRJ), Av. Horácio de Macedo 2030 Bloco I Cidade Universitária, Rio de Janeiro, Brazil.

*E-mail: creis@metalmat.ufrj.br

doi: $10.20964 / 2020.01 .07$

Received: 26 April 2019 / Accepted: 26 October 2019 / Published: 30 November 2019

The aim of this study is to investigate the galvanic effect of $\mathrm{NiCr}$ on Ti6Al4V in fluoride solutions used on dental implants rehabilitations. The alloys were evaluated in solutions with different contents of fluoride and $\mathrm{pH}$ in similar conditions founded in oral environment. The electrochemical measurements were performed on two steps. On the first step, analysis of the open circuit potential of each alloy in combination with various fluoride concentrations and $\mathrm{pH}$ values were carried out. In the second step, galvanic measurements were performed between the coupled alloys using precision multimeters. Data were evaluated by one-way ANOVA tests $(\alpha=0.05)$. Ti6Al4V presented a decreasing corrosion resistance with increasing fluoride concentration and decreasing $\mathrm{pH}$, being in a thermodynamic corrosion domain for all evaluated solution combinations except $227 \mathrm{ppm} \mathrm{\textrm {F } ^ { - }}$ at $\mathrm{pH}$ 5.5. Despite this, an important result was obtained from the galvanic measurements. When coupled with $\mathrm{NiCr}$, Ti6Al4V was 
able to achieve passivity and did not exhibit adverse galvanic effects with the different fluoride combinations tested. The possible galvanic effect in our study was an improvement in the Ti6Al4V corrosion resistance in the presence of fluoride content when it was coupled with NiCr. This study provides a new important result for the safe use of Ti6Al4V with a possible fluoride presence in the oral environment since they are associated with $\mathrm{NiCr}$-based prostheses and implant connections.

Keywords: galvanic corrosion, titanium, fluoride, implant, $\mathrm{NiCr}$

\section{$\underline{\text { FULL TEXT }}$}

(C) 2020 The Authors. Published by ESG (www.electrochemsci.org). This article is an open access article distributed under the terms and conditions of the Creative Commons Attribution license (http://creativecommons.org/licenses/by/4.0/). 